\title{
Tractor Operation Chart
}

\section{Guidelines for Safe Operation of Tractor}

- Tractors have

o Wide front ends

o Roll Over Protective Structure (ROPS) and seatbelt

o All safety features in place

- Youth

o Perform pre-operational check with adult

o Can reach all controls while wearing seatbelt

o Does not have extra riders on the tractor

o Operates tractor only in daylight and during good weather

o Avoids steep slopes and driving near ditches, trees and fences

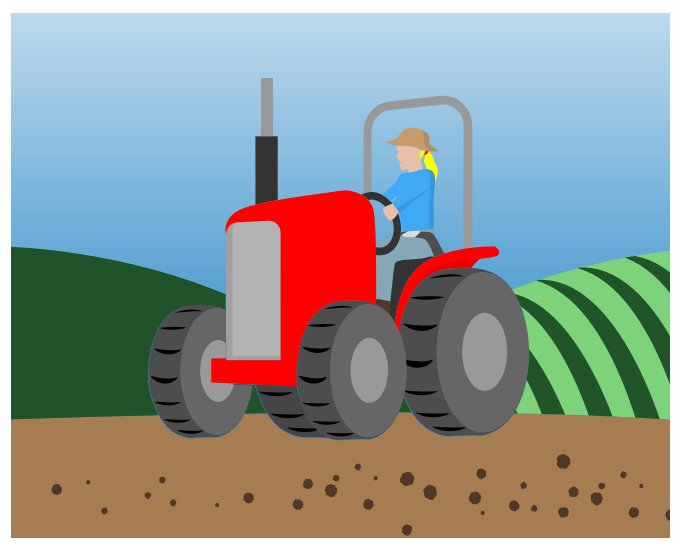

\begin{tabular}{|c|c|c|c|c|}
\hline \multirow{2}{*}{$\begin{array}{l}\text { Refer to the specific guideline } \\
\text { for recommended supervision }\end{array}$} & \multicolumn{4}{|c|}{ Size of Tractor } \\
\hline & UTILITY & $\begin{array}{l}\text { SMALL } \\
\text { 20hp to } 70 \mathrm{hp}\end{array}$ & $\begin{array}{l}\text { MEDIUM-LARGE } \\
\text { more than 70hp }\end{array}$ & ARTICULATED \\
\hline $\begin{array}{l}\text { Operating a Farm Tractor } \\
\text { (no equipment attached) }\end{array}$ & $14-15$ years & $14-15$ years & $14-15$ years & $16+$ years \\
\hline Trialed Implements & $14-15$ years & $14-15$ years & $14-15$ years & $16+$ years \\
\hline 3-Point Implements & $14-15$ years & $14-15$ years & $14-15$ years & $16+$ years \\
\hline Remote Hydraulics & $14-15$ years & $14-15$ years & $14-15$ years & $16+$ years \\
\hline PTO-Powered Implements & $14-15$ years & $14-15$ years & $14-15$ years & $16+$ years \\
\hline Tractor-Mounted Front-End Loader & $14-15$ years & $16+$ years & $16+$ years & $16+$ years \\
\hline Working in an Orchard & $14-15$ years & $16+$ years & $16+$ years & $16+$ years \\
\hline Working Inside Buildings & $14-15$ years & $16+$ years & $16+$ years & $16+$ years \\
\hline Driving on Public Roads* & $\mathrm{N} / \mathrm{A}$ & $16+$ years & $16+$ years & $16+$ years \\
\hline \multicolumn{5}{|l|}{$\begin{array}{l}\text { Pulling Oversize or Overweight } \\
\text { Loads }\end{array}$} \\
\hline \multicolumn{5}{|l|}{$\begin{array}{l}\text { Hitching Tractor to Move } \\
\text { Stuck/lmmovable Object }\end{array}$} \\
\hline $\begin{array}{l}\text { Simultaneous Use of Multiple } \\
\text { Vehicles }\end{array}$ & \multirow{3}{*}{\multicolumn{4}{|c|}{$\begin{array}{l}\text { Due to increased hazard and complexity, } \\
\text { these jobs should NOT be assigned to youth. }\end{array}$}} \\
\hline $\begin{array}{l}\text { Additional Persons on a Trailing } \\
\text { Implement }\end{array}$ & & & & \\
\hline $\begin{array}{l}\text { Pesticide or Anhydrous Ammonia } \\
\text { Application* }\end{array}$ & & & & \\
\hline${ }^{*}$ follow state/province laws & & & & \\
\hline
\end{tabular}

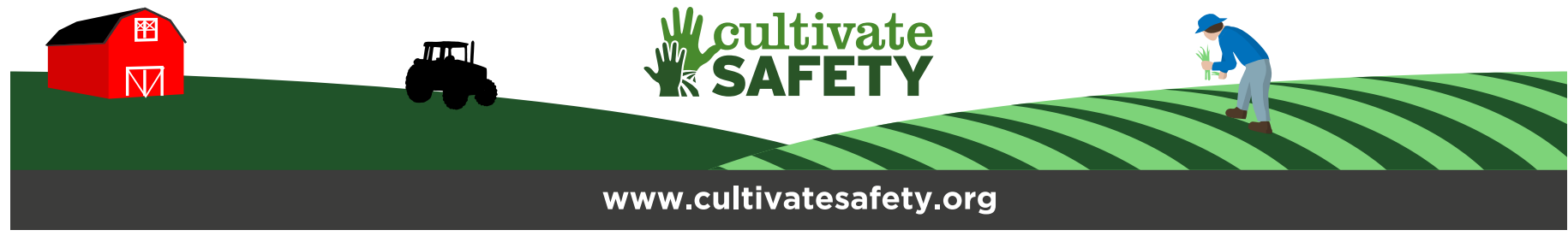

